\title{
A cross-cultural study on perceived lighting quality and occupants' well-being between UK and South Korea
}

\author{
Dong Hyun Kim* and Kevin. P. Mansfield
}

Institute for Environmental Design and Engineering (IEDE), The Bartlett Faculty of the Built

Environment, University College London, Central House, 14 Upper Woburn Place, London WC1H 0NN, UK

* Corresponding author.

Email address: dong.kim@ucl.ac.uk (D. H. Kim) 


\title{
A cross-cultural study on perceived lighting quality and occupants' well-being between UK and South Korea
}

\begin{abstract}
The path leading from lighting quality through preference and mood to human health and well-being was defined as the 'Appraisal Path' by Veitch et al. (2008). This study aims to investigate the appraisal path under uncontrolled cafes, and to compare the results between daylit and non-daylit cases as well as the cultural differences between the UK and South Korea. A daylit café and a nondaylit café were chosen for the field survey both in London and Seoul. Then, customers' experiences and feelings in the cafes were investigated by using a customized questionnaire, in terms of quality of lighting, feelings, attractiveness, satisfaction and eye discomfort. 66 customers (49 for daylit, 17 for non-daylit) were randomly selected and questioned in London and 102 customers (62 for daylit, 40 for non-daylit) participated in the field survey in Seoul. As a result, four different appraisal paths were found. No significant relationship was found between perceived lighting quality and perceived eye discomfort at daylit cafes in both London and Seoul. On the other hand, it was found that perceived lighting quality was a key determinant factor on perceived eye discomfort regardless of the cultural differences at non-daylit cafes. However, there was a significant cultural difference in factors affecting perceived lighting quality.
\end{abstract}

\section{Keywords}

Occupant well-being; Lighting quality; Appraisal path; Eye discomfort; Health 


\section{Introduction}

Lighting is often regarded as one of the highest consumers of electricity in buildings [1] and therefore it is important for energy-efficient building design to displace the need for electricity used in indoor lighting. However, sustainable approaches should not only focus on environmental and economic benefits but also on social benefits such as enhancing occupants' comfort and health as well as improving the overall quality of life [2]. Since the late 1990's, the CIE (Commission Internationale de l'Éclairage) has shifted its emphasis from lighting for visibility to a more broad definition of lighting quality, encompassing human needs, architectural integration and economic constraints including energy [3]. Many lighting research studies have established clear relationships between the lit environment and visual performance and visual comfort that are reflected in present-day lighting recommendations [4]. Also, many studies of lighting control systems have demonstrated positive impacts on overall energy reduction in use $[5,6]$ and these are brought together by the rapid improvements in lamp, ballast and luminaire technology [7].

However, it seems as if an understanding of the effects of indoor lighting quality on occupants' various behaviour that leads to health and well-being is still vague. In particular, questions remain as to the possibility that lighting conditions might be further improved beyond the visual task recommendation level to the point at which they could become positive contributors to employee productivity, mood and well-being [8].

Several investigations have pointed out the effects of light distribution and the availability of individual control on human behavioural outcomes. In terms of lighting distribution, several studies have suggested that the use of both direct and indirect lighting were preferred over direct-only systems $[9,10,11]$. Surveys consistently reported a preference for individual control of indoor environmental elements and the positive effects in the work environment on both energy consumption and office workers' moods. For example, with regard to HVAC studies, Fisk and Almeida [12] reported that sensor-based demand-controlled ventilation (SBDCV) offered better control of indoor pollutant concentrations, and lower energy use. Several studies from Singapore and Denmark 
indicated that a personalised ventilation (PV) system not only reduced total energy consumption but also provided better thermal comfort $[13,14,15]$.

In terms of lighting research, Boyce et al. [9] found that individually controllable lighting conditions were rated as more comfortable by a larger percentage of people than conventional fixed conditions. However, Veitch and Newsham [16] reported no simple effects of individual control over lighting on task performance, mood, or satisfaction. Later, they reanalysed the data from participants without control and found that people whose working conditions were more close to their personal preference showed improved mood and higher ratings of lighting satisfaction and overall environmental satisfaction [17].

Based on the literature, it seems that although changes in some components of the lit environment affect occupants' or employees' behaviours, the path from the lit environments to employees' behavioural outputs is not clear compared to other elements of indoor environmental quality. It is argued that there have been only a few formal attempts to develop relevant analytical descriptions of a linkage between the physical variables of the lit environment and various human behavioural outcomes [18].

One attempt to link the lit environment and the psychological effects of light and lighting was the introduction of the linked mechanisms map. The concept of the linked mechanisms map was introduced as a well-conducted research tool that aims to provide practical guidance on developing such linkages. Boyce et al. [9] conducted a field simulation study to test the effects of lighting systems on performance and well-being and the hypotheses concerning the linked mechanisms were confirmed. Later, Veitch, Newsham, and Jones [17] reanalysed the data reported by Boyce et al. [9] and built a conceptual model from a series of mediated linked regressions. The conceptual model is shown in Figure 1 and proposes two paths: the APPRAISAL PATH and the VISION PATH.

In particular, the appraisal path was the most strongly supported in their study. This path led from the appraisal of lighting quality toward judgements of the preference of the space. This, in turn, led to an 
improvement of mood (affect), which in turn predicted end-of-day physical and visual health and well-being. In the present study, health and well-being was defined as the sum of measured environmental satisfaction and perceived eyestrain. In summary, the appraisal path suggests that better perceived lighting quality results in better occupants' moods and well-being by affecting various psychological responses.

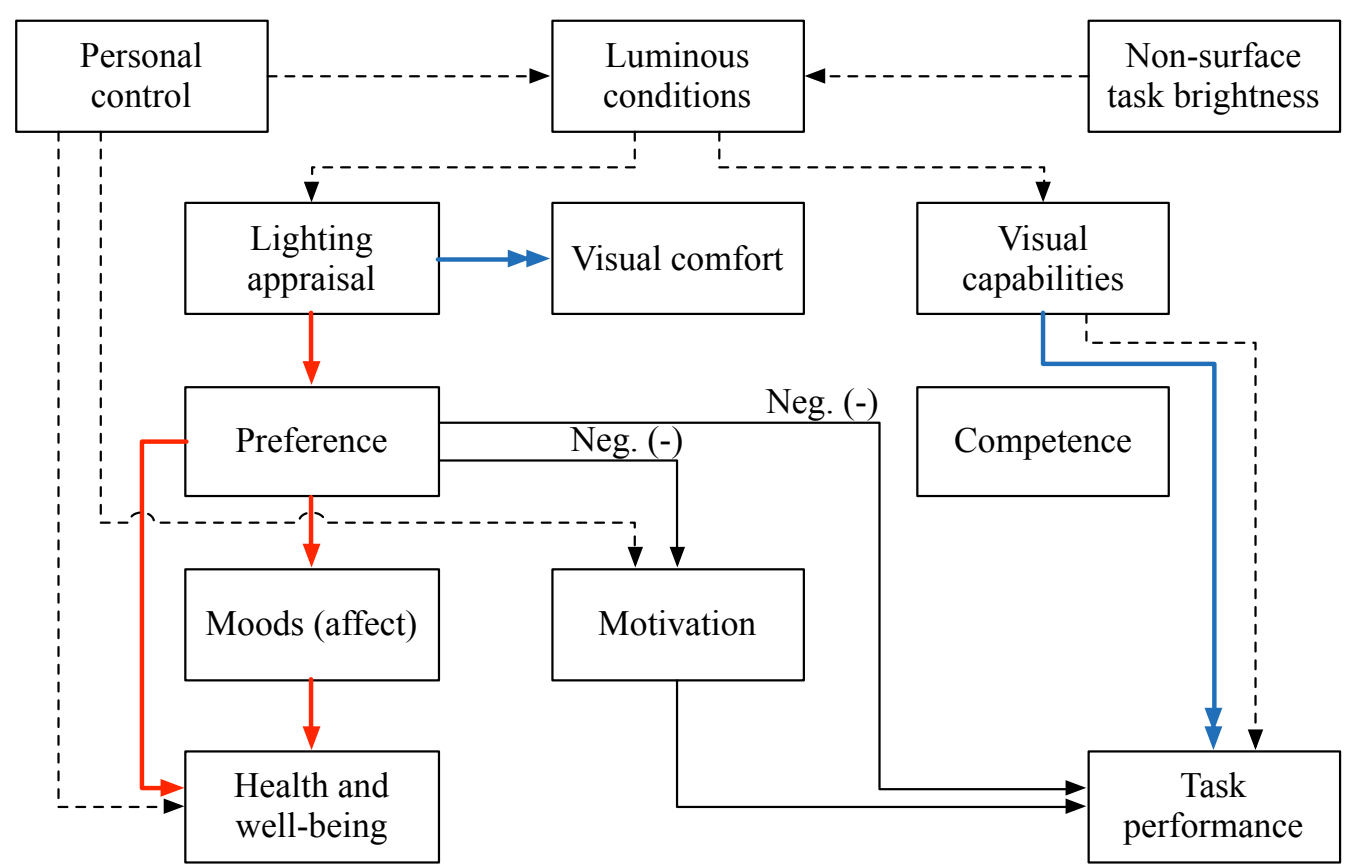

Figure 1. The modified linked mechanisms map suggested by Veitch et al. [17]

Note: The map shows lighting condition test results with dotted lines, and mediated regression test results with solid lines. Red solid lines show the APPRAISAL path, and Blue solid lines with double-headed arrows show the VISION path.

Although the appraisal path shows a complete psychological pathway from lighting quality to occupants' health and well-being, it is still not clear what elements of lighting quality particularly affect each psychological response. Also, the effects of daylighting on employees' psychological responses were not considered in the study. Moreover, the study was conducted in a controlled experimental space, which might not represent the real world situation. The present study starts from questioning the above statements and expands the idea to analyse the possible cultural differences between the UK and South Korea regarding the role of perceived lighting quality on occupants' psychological well-being. 
The hypotheses proposed in the paper are as follows:

Hypothesis 1: There is a difference in the appraisal path between controlled and uncontrolled indoor environments.

Hypothesis 2: There is a difference in the appraisal path between daylit and non-daylit indoor spaces. Hypothesis 3: There is a cultural difference in the appraisal path between the UK and South Korea.

\section{Research Methods}

\subsection{Field survey}

The study involved two field surveys which were conducted in London, UK, from $27^{\text {th }}$ July 2012 to $9^{\text {th }}$ August 2012; the other was conducted in Seoul, South Korea, from $25^{\text {th }}$ September 2012 to $10^{\text {th }}$ October 2012. In order to test Hypothesis 2, one daylit café and one non-daylit café were surveyed in each country. In total, four different indoor cafes were chosen for the field surveys and their floorplans and physical features are demonstrated and summarized in Figure 2 and Table 1 respectively.

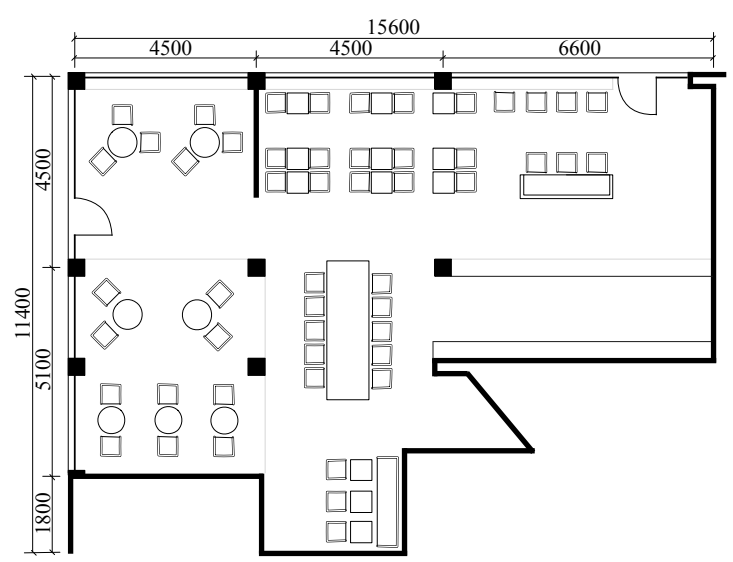

(a) Daylit café in London

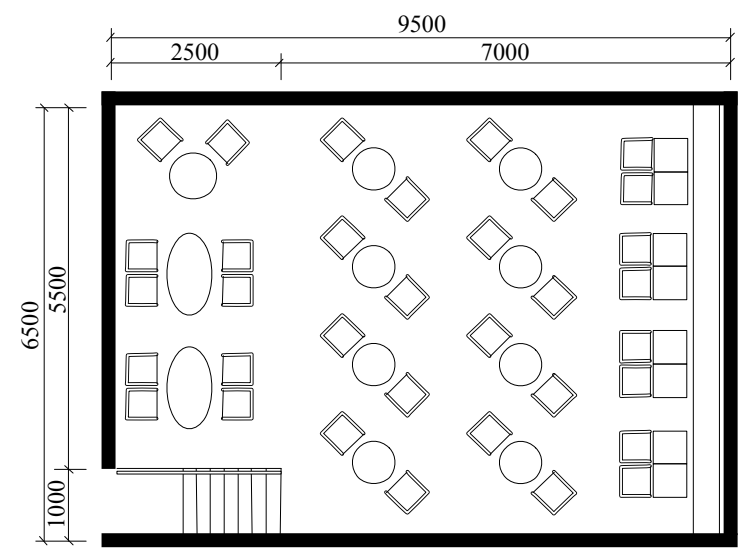

(b) Non-daylit café in London 


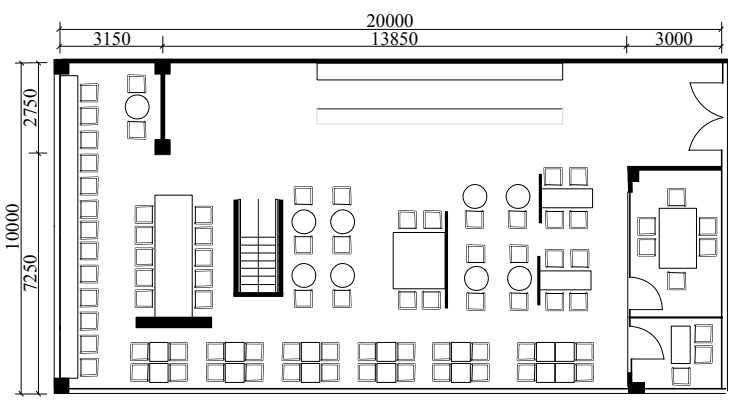

(c) Daylit café in Seoul

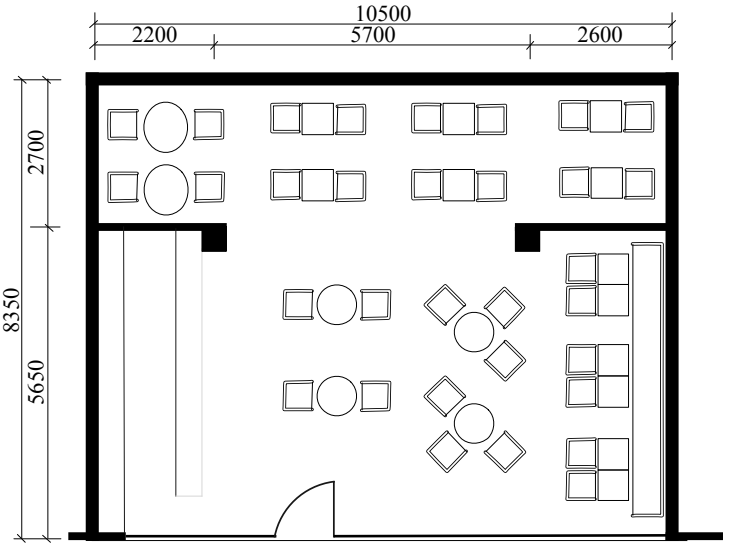

(d) Non-daylit café in Seoul

Figure 2. Floorplans of the four cafés for the field survey

Table 1 Features of the four cafes for the field survey.

\begin{tabular}{|c|c|c|}
\hline & London, UK & Seoul, South Korea \\
\hline Daylit cafe & $\begin{array}{l}\text { Located on ground floor of a building at } \\
\text { University College London. } \\
\text { - } \quad \text { More than } 20 \text { tables accommodating } \\
\text { approximately } 70 \text { customers. } \\
\text { - Average horizontal illuminance at table } \\
\text { height was } 10001 \mathrm{x} \text { and } 25001 \mathrm{x} \text {. }\end{array}$ & $\begin{array}{l}\text { - } \text { Located on the } 1^{\text {st }} \text { floor of the YBM } \\
\text { English language institute. } \\
\text { - } \quad \text { More than } 40 \text { tables accommodating } \\
\text { approximately } 100 \text { customers. } \\
\text { - Average horizontal illuminance at } \\
\text { table height was } 400-20001 \mathrm{x} \text {. }\end{array}$ \\
\hline $\begin{array}{c}\text { Non-daylit } \\
\text { cafe }\end{array}$ & $\begin{array}{l}\text { - Located on the lower ground floor of a } \\
\text { building at University College London. } \\
\text { Approximately } 20 \text { tables accommodating } \\
\text { up to } 40 \text { customers. } \\
\text { Average horizontal illuminance at table } \\
\text { height was } 500-6001 x \text {. }\end{array}$ & $\begin{array}{l}\text { - Located on the lower ground floor of } \\
\text { a building at Korea University. } \\
\text { - Approximately } 20 \text { tables } \\
\text { accommodating up to } 40 \text { customers. } \\
\text { - } \text { Average horizontal illuminance at } \\
\text { table height was } 350-500 \text { lx. }\end{array}$ \\
\hline
\end{tabular}

\subsection{Respondents}

Respondents were randomly selected during the field survey. In total 178 respondents took part in the field survey in London and Seoul. In both field surveys, customers who worked with their laptops after at least half an hour staying in the café were asked complete a questionnaire in order to provide enough adaptation time for the indoor luminous condition. From $27^{\text {th }}$ July 2012 to $9^{\text {th }}$ August 2012, a total of 66 respondents participated the field survey study in London. An overall 102 respondents took part in the field survey from $25^{\text {th }}$ September 2012 to $10^{\text {th }}$ October 2012 in Seoul. Table 2 demonstrates features of the respondents in this study. 
Table 2 Number of respondents in the field surveys in the UK and South Korea.

\begin{tabular}{ccc}
\hline & London, UK & Seoul, South Korea \\
\hline Daylit Cafe & 49 (Male: 20 Female: 29) & 62 (Male: 25 Female: 37$)$ \\
Non-daylit Cafe & 17 (Male: 10 Female: 7) & 40 (Male: 19 Female: 21$)$ \\
Total & 66 (Male: 30 Female: 36) & 102 (Male: 44 Female: 58$)$ \\
\hline
\end{tabular}

\subsection{Survey method and questionnaire design}

Respondents were given a four-page questionnaire regarding their experience and feelings in the cafes. There was a total of 23 questions in the survey, which can be broken down into six groups: general information about the respondents (4 items), perceived lighting quality ( 7 items), perceived mood (2 items), perceived appearance ( 2 items), perceived environmental satisfaction with the physical environments (4 items) and perceived eye discomfort (4 items). Table 3 summarizes dependent variables used in the five categories (excluding the general information).

Table 3 Dependent variables in the field survey.

\begin{tabular}{llll}
\hline Construct & Dependent variables & Label & Scale \\
\hline Lighting quality & Reflection & LQ_REFLECTION & $1-5$ (higher is better) \\
& Flicker & LQ_STABILITY & $1-5$ (higher is better) \\
Brightness & LQ_BRIGHTNESS & $1-5$ (higher is brighter) \\
Colour rendering & LQ_COLOUR & $1-5$ (higher is better) \\
Distribution & LQ_DISTRIBUTION & $1-5$ (higher is better) \\
Shadows & LQ_SHADOW & $1-5$ (higher is better) \\
& Overall Comfort & LQ_COMFORT & $1-5$ (higher is better) \\
& Aroused - sleepy & MOOD_SLEEPINESS & $1-9$ (higher is 'sleepy') \\
Unpleasant- pleasant & MOOD_PLEASANTNESS & $1-9$ (higher is 'pleasant')
\end{tabular}




$\begin{array}{llll}\text { Lighting appearance } & \text { Attractiveness } & \text { ATTRACTIVENESS } & 1-5 \text { (higher is better) } \\ \text { Environmental } & \text { Efficiency } & \text { SAT_EFFICIENCY } & 1-5 \text { (higher is better) } \\ \text { satisfaction (with the } & \text { Overall Satisfaction } & \text { SAT_SATISFACTION } & 1-5 \text { (higher is better) } \\ \text { physical environment) } & \begin{array}{l}\text { Suitability to the tasks } \\ \text { Preference }\end{array} & \text { SAT_SUITABILITY } & 1-5 \text { (higher is better) } \\ \text { Eye discomfort } & \text { Negative sensitivity } & \text { DAT_LIKED } & 1-5 \text { (higher is better) } \\ & \text { Redness } & \text { DISCOM_RE_REDNESS } & 1-5 \text { (lower is better) } \\ & \text { Tiredness } & \text { DISCOM_TIREDNESS } & 1-5 \text { (lower is better) } \\ & \text { Dryness } & \text { DISCOM_DRYNESS } & 1-5 \text { (lower is better) }\end{array}$

To test the effectiveness of the questionnaire, a pilot study was carried out from $23^{\text {rd }}$ to $24^{\text {th }}$ July 2012 in London. Participants in the pilot group consisted of twelve people, with a mix of job roles, educational background, and proficiency in English. Half of them had an educational background of lighting designer or architectural designer. The questionnaire was updated following comments from the pilot group.

\subsection{Variable definitions}

- Lighting quality: Seven questions were asked of respondents to self-report their scale of perceived lighting quality by using a five-point Likert scale, ranging from "Strongly disagree" to "Strongly agree". The variables were chosen and modified from the Office Lighting Survey [19]. Label: LQ_*

- Mood: Mood was assessed using the Affect Grid [20], which is a simple measure of pleasure and arousal. Label: MOOD_*

- Appearance: Self-ratings of attractiveness of the surrounding luminous environments by using a five-point Likert scale, ranging from "Not at all" to "Completely". Label: ATTRACTIVENESS 
- Environmental satisfaction: Four questions were asked of respondents to self-report their scale of perceived satisfaction level by using a five-point Likert scale, ranging from "Not at all" to “Completely". Label: SAT_*

- Eye Discomfort: Four questions asked respondents to self analyse their symptoms of eye discomfort by using a five-point Likert scale, ranging from "Not at all" to "Completely". Label: DISCOM_*

All the dependent variables measured were tested and were shown to have high enough internal consistency reliability for the use of statistical analysis (Cronbach's $\alpha>0.8$ ).

\subsection{Statistical analysis}

In this study, multiple regression analysis was used to define the appraisal paths. This is a logical sequence of multiple regression analyses used to examine whether the influence of one variable (X) on another (Y) is partly or wholly explained by the influence of X.

The normality of response distribution was tested using Kolmogorov-Smirnov. For non-normal distributions of responses, the Mann-Whitney and Kruskal-Wallis tests were used to identify the difference and correlations between variables. For nominal-scale data, dummy regression analysis was used to test associations between variables. In interpreting the findings, three indicators were used as follows:

- The statistical significance of the regression analysis, using $p<0.05$ as a criterion;

- The percentage of variance explained (adj. $R^{2}$ ), using Cohen's guidelines for small (1\%), medium $(9 \%)$ and large effects (25\%) [21];

- The unstandardized regression coefficient $(\beta)$, to compare the size of the effect of $\mathrm{X}$ on $\mathrm{Y}$.

The software package SPSS 20.0 was used for all the statistical analyses in this study. 


\section{Results}

For convenience, the appraisal path developed by Veitch et al. [17] has been extracted from the linked mechanisms map and is shown in Figure 3. The dependent variables explored in this study are shown together with the relevant items on the appraisal path.

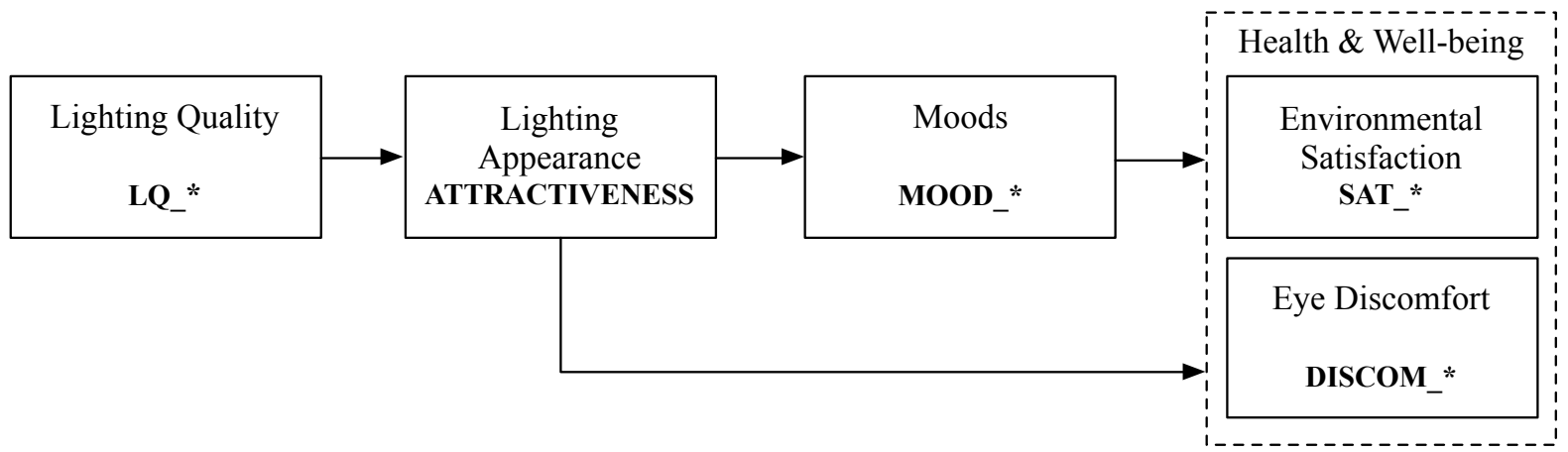

Figure 3. The appraisal path developed by Veitch et al. [17].

Note: Dependent variables are shown in bold.

\subsection{Appraisal paths under the daylit cafés}

\subsubsection{The appraisal path in London, UK}

Multiple linear regression analysis was conducted in this study to explore the correlations between the dependent variables. As shown in Figure 4(a), the sole example of a strong correlation was between Lighting Quality and Lighting Appearance (adj. $\left.R^{2}=.369, p<0.001\right)$. Perceived brightness and comfort level were the only lighting quality factors that affected the attractiveness of the lit appearance of the café with the level of brightness $(\beta=.501)$ having a stronger influence than the comfort level $(\beta=.361)$.

Lighting Quality and Moods were moderately correlated (adj. $\left.R^{2}=.236, p<0.001\right)$ with the perceived level of comfort being the only lighting quality factor to affect the MOOD_PLEASANT variable in this path. Lighting Quality and Environmental Satisfaction were moderately correlated (adj. $R^{2}=.199$, $p<0.05)$ and perceived reflections and levels of comfort affected the overall level of Environmental 
Satisfaction. Here perceived comfort $(\beta=.317)$ had a slightly stronger influence than reflections $(\beta=.294)$. Moderate correlations were also found between Lighting Appearance and Moods (MOOD_PLEASANT) $\left(\operatorname{adj} . R^{2}=.237, \mathrm{p}<0.01\right)$ and between Lighting Appearance and Environmental Satisfaction (adj. $\left.R^{2}=.187, p<0.001\right)$.

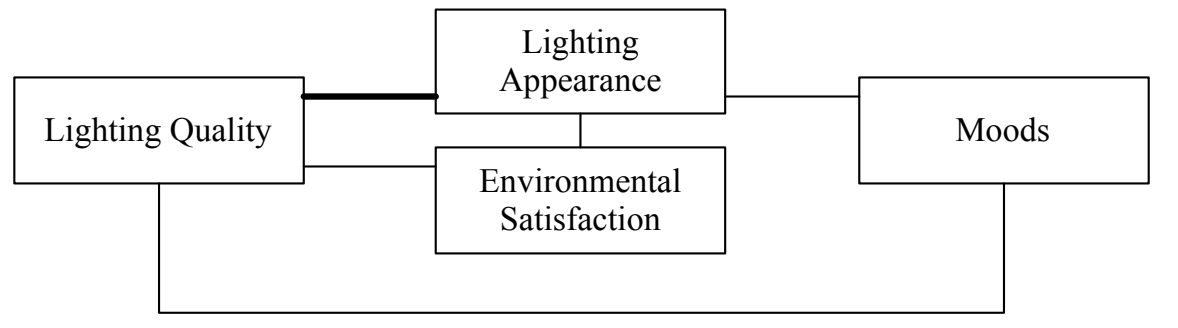

Eye Discomfort

(a) Appraisal path under daylit café in London, UK ( $\mathrm{N}=49) .{ }^{*}$

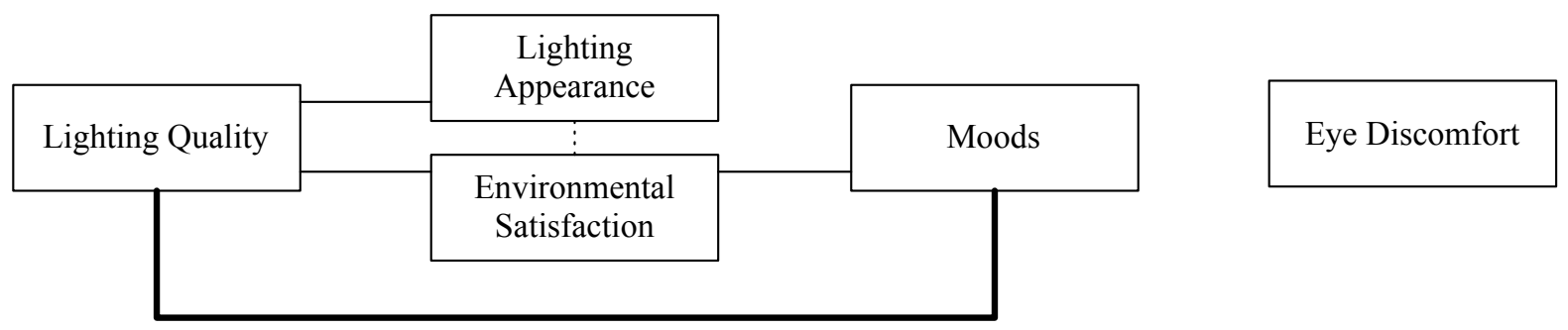

(b) Appraisal path under daylit café in Seoul, South Korea $(\mathrm{N}=62){ }^{*}$

Figure 4. Appraisal paths under daylit cafés in London and Seoul.

${ }^{*}$ Thick solid lines indicates strong correlations (adj $R^{2} \geq 0.25$, $p$-value $<0.05$ ), solid lines indicates medium correlations $\left(0.09 \leq \operatorname{adj} R^{2}<0.25, p\right.$-value $\left.<0.05\right)$ and a dotted line indicates a weak correlation $\left(\operatorname{adj} R^{2}<0.09, p\right.$-value $\left.<0.05\right)$.

\subsubsection{The appraisal path in Seoul, South Korea}

The statistical analysis showed that Lighting Quality was strongly correlated with Moods (adj. $\left.R^{2}=.293, p<0.001\right)$ and moderately correlated with both Lighting Appearance (adj. $\left.R^{2}=.183, p<0.05\right)$ and Environmental Satisfaction (adj. $R^{2}=.223, p<0.001$ ) (see Figure 4(b)). The level of perceived comfort (LQ_COMFORT) was the only lighting quality factor to affect the above three variables. Moods was also moderately correlated with both Lighting Appearance $\left(\operatorname{adj} . R^{2}=.113, p<0.05\right)$ and Environmental Satisfaction (adj. $R^{2}=.196, p<0.05$ ). Along these paths, perceived level of pleasantness was the only mood factor that was influential. Lastly, a weak correlation $\left(\operatorname{adj} . R^{2}=.088, p<0.05\right)$ was found between Lighting Appearance and Environmental Satisfaction. 


\subsubsection{Overall analysis}

Hypothesis 1 is tested and proven by the different appraisal paths found in the daylit café (Figures 4(a) and (b)) compared to that found in the original Veitch et al. study (Figure 3). Firstly, Lighting Quality influences not just Moods and Lighting Appearance but also Environmental Satisfaction level in the daylit cafes. Secondly, no statistically strong correlation was found between Eye Discomfort, originally referred to as health in the Veitch study, and any variables in the appraisal paths.

With regard to the hypothesis 3 , there are several examples of cross-cultural differences in the appraisal paths. Firstly, some similarities were found. Overall connections in both the appraisal paths were identical but with differences in strength of correlation. Perceived comfort level was the most important factor of Lighting Quality that affects Moods, Lighting Appearance and Environmental Satisfaction in both London and Seoul. In order to determine the factors of the luminous conditions that influenced perceived comfort level, multiple linear regressions (stepwise method) were conducted. Table 4 shows the result of multiple regression analyses between lighting quality variables and perceived comfort in the London case. It was found that perceived lighting distribution and colour rendering were strong factors $\left(\operatorname{adj} . R^{2}=.337, p<0.001\right)$ affecting perceived comfort level. It is statistically significant that the effects of lighting distribution $(\beta=.530)$ were stronger than the effects of colour rendering $(\beta=.249)$ on perceived comfort level.

Table 4 Multiple regression analysis between LQ variables and perceived comfort in London.

\begin{tabular}{llllll}
\hline & B & SE & $\beta$ & T & $p$-value \\
\hline (Constant) & 1.005 & .593 & & 1.695 & .097 \\
LQ_DISTRIBUTION & .503 & .113 & .530 & 4.448 & $<0.001$ \\
LQ_RENDERING & .298 & .143 & .249 & 2.092 & .042 \\
\hline & $R^{2}\left(\operatorname{adj} . R^{2}\right)=.365(.337) \mathrm{F}=12.953 p<0.001$ & & & \\
\hline
\end{tabular}


There was a cross-cultural difference found in this matter. Table 5 shows the result of the same analyses in the case of Seoul. Perceived reflection was the only factor, affecting perceived comfort level.

Table 5 Multiple regression analysis between LQ variables and perceived comfort in Seoul.

\begin{tabular}{llllll}
\hline & $\mathrm{B}$ & $\mathrm{SE}$ & $\beta$ & $\mathrm{T}$ & $p$-value \\
\hline (Constant) & 2.370 & .592 & & 4.003 & $<.001$ \\
LQ_REFLECTION & .449 & .143 & .458 & 3.135 & .003 \\
\hline \multicolumn{7}{l}{$R^{2}\left(\operatorname{adj} . R^{2}\right)=.210(.188) \mathrm{F}=9.826$} & $p=0.003$ \\
\hline
\end{tabular}

\subsection{Appraisal paths under the non-daylit cafés}

The same analysis methods were conducted for the non-daylit café cases in both London and Seoul.

Figures 5(a) and 5(b) show the appraisal paths that were discovered.

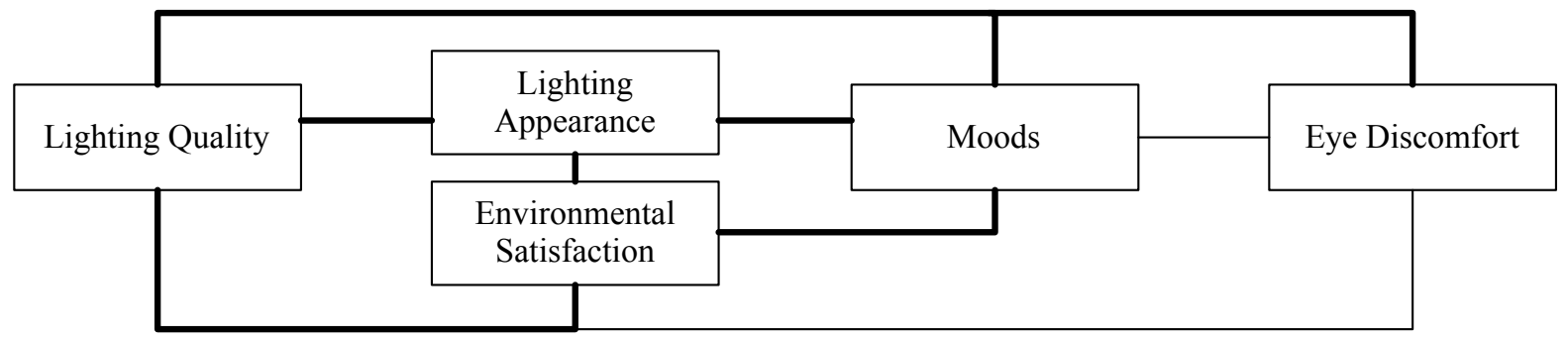

(a) Appraisal path under non-daylit café in London, $\mathrm{N}=17^{*}$

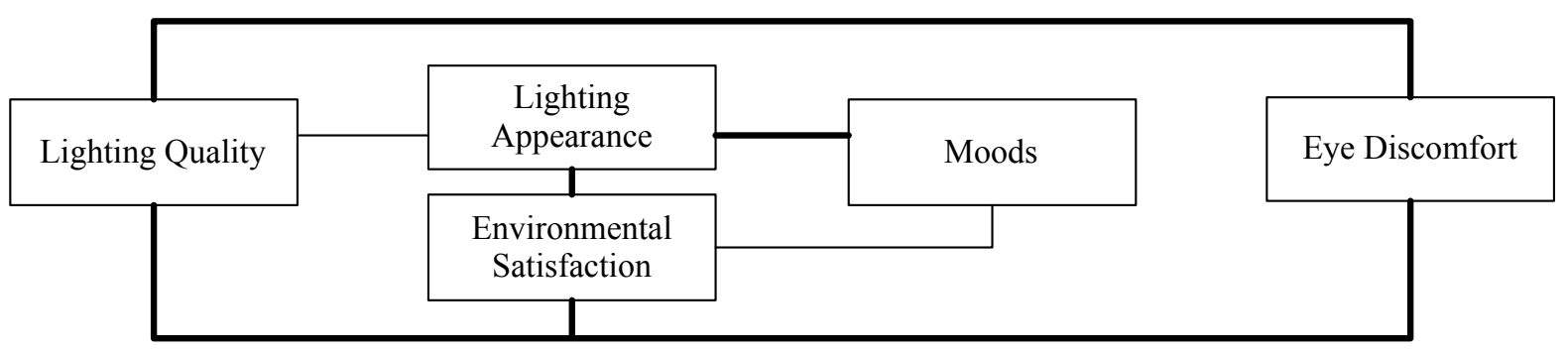

(b) Appraisal path under non-daylit café in Seoul, $\mathrm{N}=40^{*}$

Figure 5. Appraisal paths under non-daylit cafés in London and Seoul

${ }^{*}$ Thick solid lines indicate strong correlations (adj $R^{2} \geq 0.25, p$-value $<0.05$ ), solid lines indicate medium correlations $\left(0.09 \leq \operatorname{adj} R^{2}<0.25, p\right.$-value $\left.<0.05\right)$ and a dotted line indicates a weak correlation (adj $R^{2}<0.09, p$-value $\left.<0.05\right)$. 


\subsubsection{The appraisal path in London, UK}

Here many of the elements of the appraisal path show strong correlations (see Figure 5(a)). Lighting Quality was strongly correlated with Environmental Satisfaction $\left(\operatorname{adj} . R^{2}=.316, p<0.05\right)$ and Eye Discomfort (adj. $R^{2}=.517, p<0.001$ ). On these two paths, perceived comfort level was the only factor to influence both Environmental Satisfaction and Eye Discomfort. Lighting Quality was also found to be strongly correlated with Lighting Appearance (adj. $R^{2}=726, p<0.001$ ) and Moods (adj. $R^{2}=.616$, $p<0.001)$. In the first path, three lighting quality factors influenced Lighting Appearance: perceived comfort $(\beta=.615)$, lighting distribution $(\beta=.335)$ and colour rendering $(\beta=.336)$. For the latter path, perceived comfort $(\beta=.615)$ and lighting distribution $(\beta=.405)$ were lighting quality factors affecting the level of pleasantness assessed by the respondents. Moods were found to be strongly correlated with Lighting Appearance $\left(\operatorname{adj} . R^{2}=.364, p<0.01\right)$ and Environmental Satisfaction $\left(\operatorname{adj} . R^{2}=.353, p<\right.$ 0.01). Environmental Satisfaction was, uniquely, positively correlated with sleepiness suggesting that the respondents in the non-daylit café in London perceived the appearance of lighting as more attractive when they felt sleepier. To complete the analysis, Environmental Satisfaction was strongly correlated with Lighting Appearance $\left(\operatorname{adj} . R^{2}=.353, p<0.01\right)$ and a moderate correlation between Moods and Eye Discomfort (adj. $R^{2}=.213, p<0.05$ ) showing the importance of pleasantness level as a lighting quality factor.

\subsubsection{The appraisal path in Seoul, South Korea}

Five strong correlations and two moderately strong correlations were found on the appraisal path (see Figure 5(b)). Lighting Quality was strongly correlated (adj. $\left.R^{2}=.485, p<0.001\right)$ with Environmental Satisfaction and perceived comfort $(\beta=.646)$ and shadow $(\beta=-.529)$ were the factors that had influences. A strong correlation $\left(\operatorname{adj} . R^{2}=.250, p<0.05\right)$ between Lighting Quality and Eye Discomfort was also found. In this case, perceived comfort was the only factor affecting Eye Discomfort. 
Lighting Appearance was strongly correlated with both perceived Pleasantness (adj. $R^{2}=.588, p<0.05$ ) and Environmental Satisfaction (adj. $R^{2}=.369, p<0.01$ ). Environmental Satisfaction was also found to be strongly correlated (adj. $R^{2}=.289, p<0.01$ ) with Eye Discomfort. There was a moderately strong correlation (adj. $R^{2}=.233, p<0.05$ ) between Lighting Quality and Lighting Appearance and perceived comfort was again the only factor that influenced Lighting Quality. Lastly, a positive moderately strong correlation (adj. $R^{2}=.211, p<0.05$ ) was found between Moods and Environmental Satisfaction.

\subsubsection{Overall analysis}

Hypothesis 1 was again tested and proven by the different appraisal paths found in the non-daylit café (Figures 5(a) and (b)) compared to that found in the original Veitch et al. study (Figure 3). First, there are clear strong correlations between Eye Discomfort and Lighting Quality. Lighting Quality is directly correlated with most of the variables under the non-daylit cases. The appraisal paths in Figures 5(a) and 5(b) suggest that occupants' health and well-being have a complex relationship with Lighting Quality and its effects on other psychological variables. Hypothesis 2 was also tested and proven by the differences in the appraisal paths in the daylit and non-daylit cafés (as shown in Figures 4 and 5). For example, a significantly higher value of adj. $R^{2}$ were found both in London and Seoul under the non-daylit cafes, which resulted in greater numbers of strong correlations. The results indicate that there was a noticeable difference between the appraisal paths in the daylit and non-daylit case.

Perceived comfort level was again found to be the most important factor of Lighting Quality that had most influence on other psychological variables. Therefore, multiple regression analyses were conducted in order to determine the factors of the luminous conditions that affected perceived comfort. Tables 6 and 7 show the results of multiple regression analyses between Lighting Quality variables and perceived comfort in London and Seoul respectively. It was found that brightness level was a strong influence (adj. $R^{2}=.451, p=0.002$ ) on perceived comfort in London. Of statistical significance is 
that respondents who were satisfied with brightness level felt more comfortable with their luminous conditions.

Table 6 Multiple regression analysis between LQ variables and perceived comfort in London

\begin{tabular}{llllll}
\hline & $\mathrm{B}$ & $\mathrm{SE}$ & $\beta$ & $\mathrm{T}$ & $p$-value \\
\hline (Constant) & 2.400 & .248 & & 9.661 & $<0.001$ \\
LQ_BRIGHTNESS & 1.457 & .387 & .697 & 3.764 & .002 \\
\hline \multicolumn{5}{l}{} \\
\hline
\end{tabular}

A similar multiple regression analysis was carried out to determine the factors of perceived comfort in Seoul and the result is shown in Table 7. The analysis shows that, again, brightness level was the only factor that influenced perceived comfort.

Table 7 Multiple regression analysis between LQ variables and perceived comfort in Seoul.

\begin{tabular}{llllll}
\hline & $\mathrm{B}$ & $\mathrm{SE}$ & $\beta$ & $\mathrm{T}$ & $p$-value \\
\hline (Constant) & 3.091 & .238 & & 13.003 & $<0.001$ \\
LQ_BRIGHTNESS & 1.009 & .344 & .558 & 2.929 & .009 \\
\hline \multicolumn{7}{l}{$R^{2}\left(\operatorname{adj} . R^{2}\right)=.311(.275) \mathrm{F}=8.582 p=0.009$} \\
\hline
\end{tabular}

\section{Discussion}

This study has explored the correlation between lighting quality and occupants' health and well-being through analysis of the appraisal path obtained from two field surveys.

The results have shown large differences between the original appraisal path suggested by Veitch et al., derived from a controlled luminous environment, to those obtained in this study from uncontrolled indoor luminous environments.

One finding of this study is the clear influence that daylighting has on perceived lighting quality and 
its subsequent effect on occupant health and well-being in indoor environments. In the daylit café, occupants are less sensitive to perceived lighting quality than in the non-daylit café where a strong correlation is demonstrated with health and well-being.

Based on the findings of this study, a few recommendations can be made to lighting designers, lighting industry professionals and researchers. Firstly, the study suggests different priorities when designing daylit indoor environments. For example, providing brighter indoor environments is likely to result in better moods, appearance and ultimately occupant well-being in non-daylit environments whereas the same approach might not be so effective in daylit environments. Moreover, proper evaluation and control of lighting systems is needed to reduce energy consumption in use while providing social and mental benefits to occupants.

Secondly, different guidelines are suggested based on cultural differences. The study demonstrates that the appraisal path differs between London and Seoul. For example, the study shows that better distribution of light and improved colour rendering is likely to increase perceived comfort in London. These factors are not likely to increase perceived comfort in Seoul; here less discomfort glare is likely to increase perceived comfort level (in daylit environments).

In order to validate the findings more concretely, further field studies are recommended as the current study includes a few limitations. First, the results could be affected by the different layouts of the cafes and non-uniform illuminances on the working plane. Therefore, research that involves a variety of uncontrolled lit environments would be required to strengthen the results. Secondly, the study did not address the temporal sequencing of the data. All the variables in this study were measured in the same time block and therefore the appraisal paths that were found establish associations and not causal relationships.

Overall this study has demonstrated that the appraisal path in the linked mechanisms map can be a useful model for determining the effect of luminous conditions on occupant appraisal, preference, mood and health and well-being. The study has demonstrated that the appraisal path changes in 
character when comparing controlled lighting settings to uncontrolled settings (such as those found in the real world). Further lighting appraisal is distinctly different when comparing daylit indoor environments with those that are non-daylit. The study has also demonstrated a cultural difference in the appraisal path between the UK and South Korea and this would be worth exploring further with different cultural cohorts.

\section{References}

1 U.S Department of Energy, [online] Available from http://www.eia.gov/consumption/commercial (accessed Feb 2016).

2 U.S Environmental Protection Agency, [online] Available from http://www.epa.gov/greenbuilding (accessed Feb 2016).

3 J.A. Veitch, W. Julian, A.I. Slater, (1998) A framework for understanding and promoting lighting quality. In Proceedings of the First CIE Symposium on Lighting Quality (J.A. Veitch, ed), 237241. Vienna. CIE Central Bureau.

4 J.A.Veitch, G.R. Newsham, Determinants of lighting quality I: State of the science, Journal of the Illuminating Engineering Society 27 (1998) 92-106.

5 G.Y. Yun, H. Kim, J.T. Kim, Effects of occupancy and lighting use patterns on lighting energy consumption, Energy and Buildings 46 (2012) 152-158.

6 P.K. Soori, M. Vishwas, Lighting control strategy for energy efficient office lighting system design, Energy and Buildings 66 (2013) 329-337.

7 M.C. Dubois, A. Blomsterberg, Energy saving potential and strategies for electric lighting in future North European, low energy office buildings: a literature review, Energy and Buildings 43 (2011) 2572-2582.

8 P.R. Boyce, Lighting research for interiors: the beginning of the end or the end of the beginning, Lighting Research and Technology 36 (2004) 283-294.

9 P.R. Boyce, J.A. Veitch, G.E. Newsham, C.C. Jones, J. Heerwagen, M. Myer, C.M. Hunter, Lighting quality and office work: Two field simulation experiments, Lighting Research and Technology 38 (2006) 191-223.

10 K.W. Houser, D.K. Tiller, C.A. Bernecker, P.G. Mistrick, The subjective response to linear fluorescent direct/indirect lighting systems, Lighting Research and Technology 34 (2002) 243264. 
11 J.A. Veitch, G.R. Newsham, Preferred luminous conditions in open-plan offices: Research and practice recommendations, Lighting Research and Technology 32 (2000) 199-212.

12 W.J. Fisk, A.T. De Almeida, Sensor-based demand controlled ventilation: a review, Energy and Buildings 29 (1998) 35-45.

13 B. Yang, C. Sekhar, A.K. Melikov, Ceiling mounted personalized ventilation system in hot and humid climate - an energy analysis, Energy and Buildings 42 (2010) 2304-2308.

14 S. Schiavon, A.K. Melikov, C. Sekhar, Energy analysis of the personalized ventilation system in hot and humid climates, Energy and Buildings 42 (2010) 699-707.

15 S. Schiavon, A.K. Melikov, Energy-saving strategies with personalized ventilation in cold climate, Energy and Buildings 41 (2009) 543-550.

16 J.A. Veitch, G.R. Newsham, Exercised control, lighting choices, and energy use: An office simulation experiment, Journal of Environmental Psychology 20 (2000) 219-237.

17 J.A. Veitch, G.R. Newsham, C.C. Jones, Lighting appraisal, well-being, and performance in open-plan offices: a linked mechanisms approach, Lighting Research and Technology 40 (2008) 133-151.

18 J.A. Veitch, G.R. Newsham, S. Mancini, NRC-IRC Research Report RR-306: Lighting and Office Renovation Effects on Employee and Organizational Well-Being, National Research Council Canada Institute for Research in Construction, 2010.

19 N.H. Eklund, P.R. Boyce, The development of a reliable, valid and simple office lighting survey, Journal of the Illuminating Engineering Society 25 (1996) 25-40.

20 J.A. Russell, A. Weiss, G.A. Mendelsohn, Affect Grid: a single-item scale of pleasure and arousal, Journal of Personality and Social Psychology 57 (1989) 493-502.

21 J. Cohen, Statistical power analysis for the behavioral sciences. $2^{\text {nd }}$ edition. Hillsdale, NJ: Erlbaum, 1988 